\title{
COVID-19 outbreak, lockdown, and air quality: fresh insights from New York City
}

\author{
Khurram Shehzad $^{1} \cdot$ Faik Bilgili $^{2} \cdot$ Emrah Koçak $^{2}$ (D) $\cdot$ Liu Xiaoxing $^{1} \cdot$ Mahmood Ahmad $^{3}$ \\ Received: 17 December 2020 / Accepted: 16 March 2021 / Published online: 29 March 2021 \\ (C) The Author(s), under exclusive licence to Springer-Verlag GmbH Germany, part of Springer Nature 2021
}

\begin{abstract}
The outbreak of the COVID-19 pandemic has adversely affected all aspects of life and poses a severe threat to human health and economic development. New York City administration enacted a strict isolation decision at the end of March 2020 to tackle the COVID-19, creating a unique opportunity to assess air quality. Therefore, we investigated the impact of the lockdown on air quality in New York City. We evaluated the air pollutants concentration, i.e., $\mathrm{PM}_{2.5}, \mathrm{CO}, \mathrm{NO}_{2}, \mathrm{SO}_{2}$, and $\mathrm{O}_{3}$, during the lockdown and compared them with pre-COVID-19. We explored the first phase of lockdown through a spatial approach, then formulated the air quality index (AQI) of each pollutant before and during the lockdown. Our findings revealed that (1) there was a significant decline in the concentration level of $\mathrm{PM}_{2.5}$ from 10.3 to $4.0 \mu \mathrm{g} / \mathrm{m}^{3}$ during phase one of lockdown. (2) $\mathrm{NO}_{2}$ concentrations have been decreased by up to $52 \%$ in 1 st phase of lockdown. (3) $\mathrm{O}_{3}$ concentration has been increased by $44.4 \%$. (4) Brooklyn, Manhattan, Queens, and Staten Island County encountered 18.75\%, 55.62\%, 47.14\%, and 47\% diminution in AQI due to lockdown as compared to 2018, respectively. Our key findings can provide critical environmental implications for policymakers, researchers, academics, and the US government.
\end{abstract}

Keywords COVID-19 $\cdot$ Lockdown $\cdot$ Air pollution $\cdot \mathrm{NO}_{2} \cdot \mathrm{CO} \cdot$ Environmental quality $\cdot \mathrm{PM}_{2.5}$ concentration

Responsible Editor: Lotfi Aleya

Emrah Koçak

emrahkocak@erciyes.edu.tr

Khurram Shehzad

233189917@seu.edu.cn

Faik Bilgili

fbilgili@erciyes.edu.tr

Liu Xiaoxing

jiulonghu99@126.com

Mahmood Ahmad

mahmood_449@yahoo.com

1 School of Economics and Management, Southeast University, Nanjing, China

2 Faculty of Economics and Administrative Sciences, Department of Economics, Erciyes University, 38039 Melikgazi, Kayseri, Turkey

3 School of International Trade and Economics, University of International Business and Economics, Beijing, China

\section{Introduction}

Air pollution is one of the predominant causes and threats to human health as it leads to morbidity and fatality every year (Miri et al. 2016; Fareed et al. 2020). As per the World Health Organization (WHO) estimation, seven million people die each year due to poor air quality (WHO 2014). It is primarily as a result of the concentration of pollutants such as $\mathrm{NO}_{2}$, $\mathrm{NH}_{3}, \mathrm{PM}_{2.5}$, and $\mathrm{SO}_{2} \mathrm{CO}$. from different human actions such as mining activities, the process of manufacturing, transportation, residential cooking, biomass, and waste burnings (Kinnon et al. 2019; Li et al. 2019; Blondet et al. 2019; Koçak and Kızılkaya 2020; Dedeoğlu et al. 2021). During the past two decades, numerous studies highlighted that polluted air incites short-term and long-term health issues such as asthma, cancer, premature deaths, and cardiovascular mortality, among humans (Bowatte et al. 2017; Deng et al. 2017; Zhang et al. 2017; Gilderbloom et al. 2020; Karuppasamy et al. 2020). Park et al. (2020) observed that the population is living in the proximity of significant roadways in urban cities are suffering more from air pollution.

The emergence of severe acute respiratory syndrome coronavirus-2 (SARS-CoV-2) outbreak firstly COVID-19 
pandemic has posed a severe threat to human health and adversely affected all aspects of life (Wang et al. 2020; Zhu et al. 2020; Khoo and Lantos 2020). Moreover, Fig. 1 exhibited that up to January 02, 2021, globally, 2,217,005 people have died, and 102,399,513 infected by COVID-19, and the USA become the country having a higher number of 436,051 deaths and 25,817,939 confirmed cases (WHO 2020). Thus, the USA has accounted for $25.12 \%$, and $19.61 \%$ of worldwide COVID-19 confirmed cases and deaths, respectively. Accordingly, the COVID-19 pandemic has been announced as a global emergency that resulted in the implementation of lockdown in activities (i.e., mobility, unnecessary business, social contact) to flattening the outbreak curve.

Countries face increasingly severe air pollution challenges due to massive emissions from vehicles and industrial waste (Yang et al. 2020). However, after the restricted human activates amidst COVID-19 lockdown, globally, a significant improvement has been observed in air quality, such as the USA (Pata 2020), India (Mahato et al. 2020), Iran (Broomandi et al. 2020), China (Bao and Zhang 2020; Balsalobre-Lorente et al. 2020), Malaysia (Suhaimi et al. 2020), Spain (Baldasano 2020), Brazil (Dantas et al. 2020), and Japan (Ma and Kang 2020). The decline in air pollution is plausible due to the restrictions on human activities (He et al. 2020). Recently, the National Aeronautics and Space Administration (NASA) observed a $30 \%$ decline in the concentrations of atmospheric $\mathrm{NO}_{2}$ in the urban Northeast of the USA during March 2020 compared to the mean value of March 2015-2019 (see Fig. 2). Hence, the lockdown presents short-term benefits to the environment and air quality and poses a dual-edge threat in the long-term perspective. Firstly, while recession or economic slowdown will adversely affect countries' ongoing efforts towards climate mitigations; additionally, financial fear and rising health issues could overshadow the problem of climate change. Secondly, the sudden resumption of economic activities after the lockdown creates enormous pressure on the environment (Chakraborty and Maity 2020).

In the USA, President Trump declared a national emergency on March 13, 2020. Following the national emergency, most state governments in the USA issued business restrictions or lockdown amid a pandemic of COVID-19 in March 2020 (Solinas-Saunders 2020). The business restrictions in New York have created a unique opportunity to assess the effect of lockdown on environmental pollution. The City of New York is also known as the hub of the entire world's financial, cultural, and media capital. Due to the contagion of

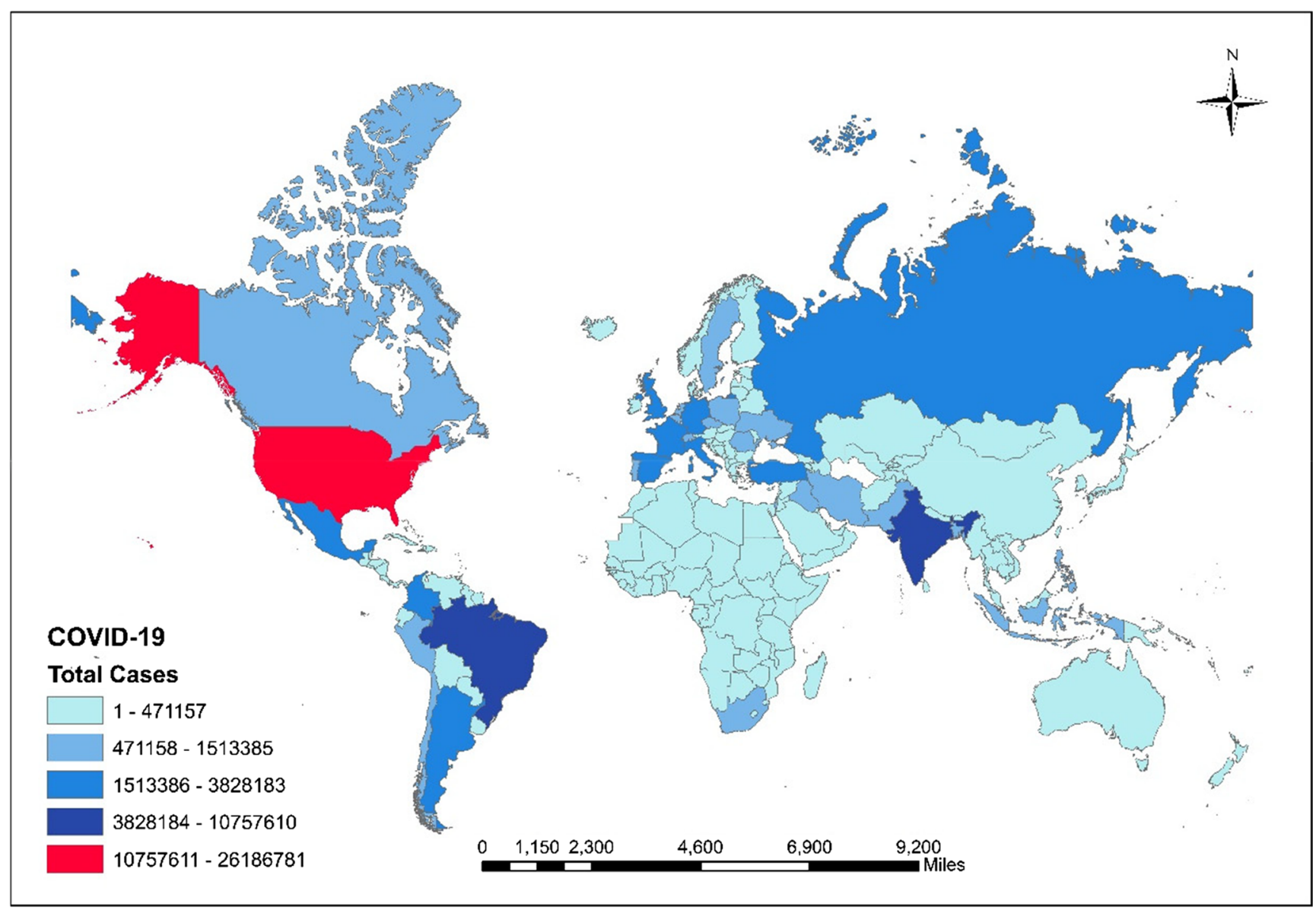

Fig. 1 Confirmed COVID-19 cases in the world. Data source: World Health Organization (2020) 


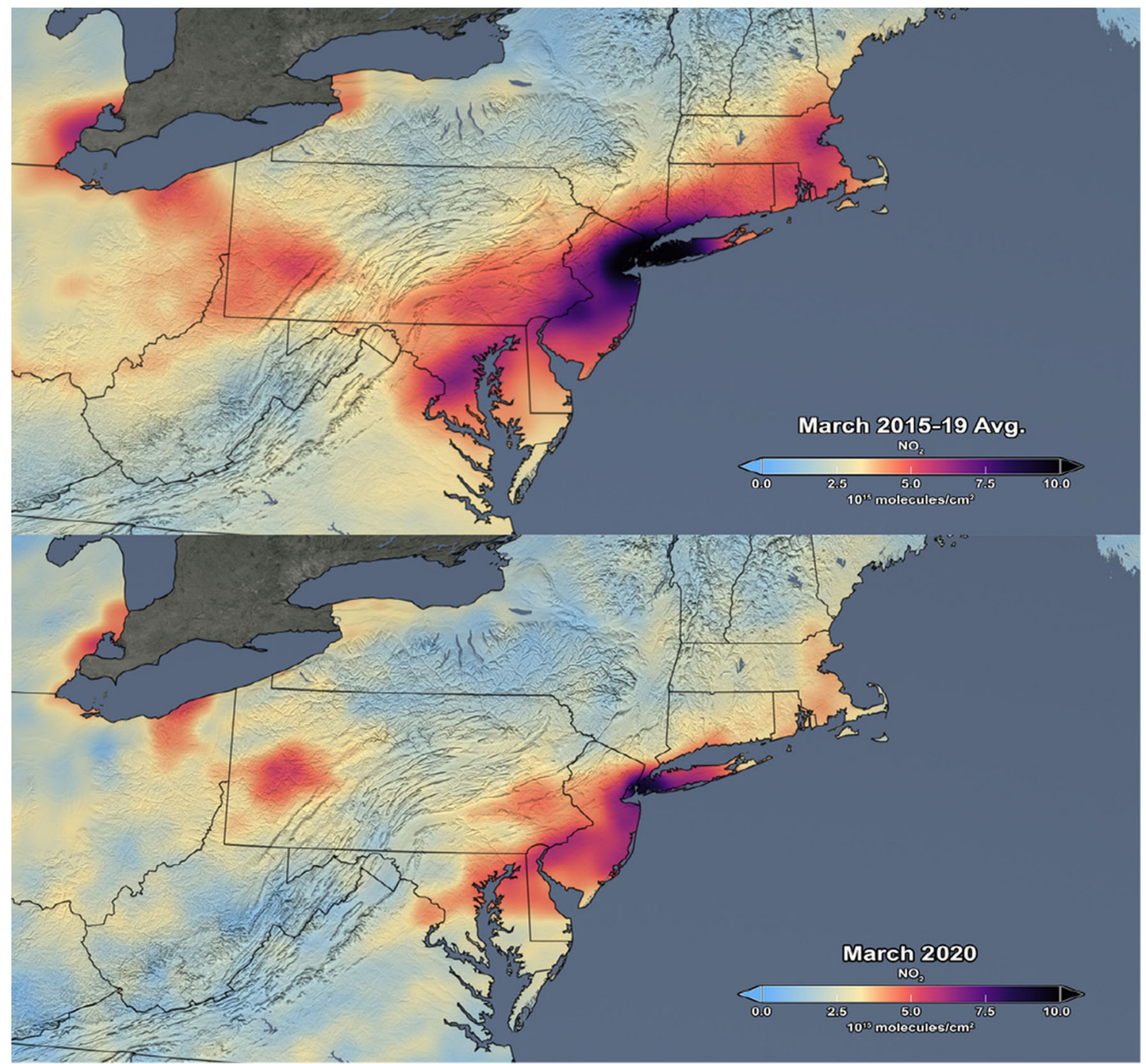

Fig. 2 Variations in $\mathrm{NO}_{2}$ emission during the lockdown in Northeast America. Source: NASA (2020)

COVID-19, a complete lockdown is imposed in New York from March 22 up to March 31 and later extended up to May 15, 2020 (for more details, see https://www.governor. ny.gov/). By this lockdown, almost all mass transportation and industrial activities have been prohibited. As a result of lockdown, the air pollution in New York City is drastically reduced even after a few days of lockdown (Pata 2020; Zangari et al. 2020).

The COVID-19 pandemic is an unprecedented situation that allows us to gauge the effect of commercial and transportation activities on local air quality. Overall, the impact and significance of lockdown are still not well understood and likely to have a significant role in the restoration of air quality (Balsalobre-Lorente et al. 2020). The extent of literature on the impact of COVID-19 pandemic lockdown on air pollutants is available; however, it is limited and covers only a few specific scenarios (Pata 2020; Suhaimi et al. 2020; Mahato et al. 2020). Previous studies have used one or a few pollutants to assess air quality during the lockdown. For instance,
Chauhan and Singh (2020) examine the concentration of $\mathrm{PM}_{2.5}$ in major cities (New York, Los Angeles, Zaragoza, Rome, Dubai, Delhi, Mumbai, Beijing, and Shanghai) around the world during the lockdown.

Similarly, Perera et al. (2021) focused on the single particulate matter $\left(\mathrm{PM}_{2.5}\right)$ during the COVID-19 shutdown. Likewise, Fu et al. (2020) analyze the effect of lockdown on air quality in 20 major cities, including New York City. Based on the argument mentioned above, we can argue that using a single or few pollutants may not present a holistic view of air quality changes during the lockdown. There is a wide variety of air pollutants. These pollutants, which have adverse effects on human health and the ecosystem, can be solid particles, liquid droplets, or gases. Pollutants can be of natural or human origin. However, pollutants are divided into two as primary and secondary pollutants. Primary pollutants are produced mainly by a process similar to a volcanic eruption, carbon monoxide released from motor vehicle exhaust, or sulfur dioxide released from industrial enterprises. Major primary pollutants are hydrogen sulfide $\left(\mathrm{H}_{2} \mathrm{~S}\right)$, 
$\mathrm{SO}_{2}, \mathrm{CO}, \mathrm{NO}_{\mathrm{x}}, \mathrm{O}_{3}$, hydrocarbons, $\mathrm{CO}_{2}, \mathrm{CH}_{4}$, lead $(\mathrm{Pb})$, and volatile organic compounds (VOCs). Secondary pollutants are not released directly; instead, they are formed by the reaction or interaction of primary pollutants in the air. Ground-level ozone is an important example of secondary pollutants. Ground-level ozone has recently been one of the important parameters followed in terms of urban air pollution, especially in developed countries. In addition, PAN (peroxyacetyl nitrate), chlorofluorocarbons (CFC), formaldehyde, ammonium sulfate, and nitric acid $\left(\mathrm{HNO}_{3}\right)$ are other important secondary pollutants (Nazaroff and Weschler 2004; Sitaras and Siskos 2008; Masiol et al. 2017). This study is different from the earlier studies on the ground that we analyze the impact of lockdown in New York City on air quality using five air pollutants, i.e., $\mathrm{CO}, \mathrm{NO}_{2}$, ozone, $\mathrm{PM}_{2.5}$, and $\mathrm{SO}_{2}$, from March 23, 2020, to May 30, 2020. Unlike the previous studies, this study also examines the county-wise variations in the air quality of New York. In doing so, this study seeks to answer the following questions. Does the concentration of air pollutants decrease during the lockdown? Does the air quality index improve during the lockdown?

This paper contributes to the literature threefold.

First, this study analyzes the behavior of various air pollutant concentrations in New York City before and during the lockdown period. Second, this study followed the methodology introduced by Environmental Protection Agency (EPA) (EPA-OAQPS 2013) and converted each pollutant into an air quality index (AQI) to ascertain its impact on the environmental quality of New York City. Additionally, this study combined all these air quality indices to formulate a complete air quality index, representing the environmental quality in New York known as NYAQI. Hence, this investigation evaluates overall air quality in New York and the role of each concentration in the environmental quality of New York before and during the lockdown epoch. The estimation findings are expected to guide the authorities in their policy design. Thirdly, this investigation performed a spatial visualization of each pollutant before the lockdown and during the 1st phase of lockdown in New York City. The spatial approach provides a better understanding of the area-wise impact of pollutants.

\section{Materials and method}

The present study has focused on New York City as it is the most populous (megacity) in the United States, with more than 8.33 million residents. The city lies between N-latitude $40^{\circ}$ $42^{\prime} 46^{\prime \prime}$ and W-longitude $74^{\circ} 00^{\prime} 22^{\prime \prime}$ with an area of about $784 \mathrm{~km}^{2}$. Geographically, the city of New York can be divided into five boroughs, viz., Bronx, State Island, Queens, Brooklyn, and Manhattan. The climate of New York can be categorized into four distinct seasons, spring (Mar-May), summer (Jun-Aug), autumn (Sept-Nov), and winter (Dec-Feb). The average temperature varies between $34^{\circ} \mathrm{F}$ to $53^{\circ} \mathrm{F}$ in spring, $63^{\circ} \mathrm{F}$ to $67^{\circ} \mathrm{F}$ in summer, $41^{\circ} \mathrm{F}$ to $60^{\circ} \mathrm{F}$ in autumn, and $26^{\circ} \mathrm{F}$ to $30^{\circ} \mathrm{F}$ in winter. New York City has a subtropical oceanic kind of weather. Despite the coastline area, temperature varies significantly between the summer and winter due to prevailing inland masses. Another critical factor is the dense urban population, which stimulates the average temperature (Depietri and McPhearson 2018; Johnson et al. 2020). The city has 10,194 per square kilometer of population density, and Manhattan has a population density of 25,846 per square kilometer that makes it the densest of the county in the United States (Plane and Mu 2020). Air pollution problems caused by motor vehicles, industries, and other fuel-burning sources are mainly responsible for critical health hazards in New York City. The American Lung Association ranked 16th New York City metropolitan area for ozone pollution when compared to 25 other American cities (Miranda et al. 2011).

This investigation guesstimates the air quality of New York City by utilizing the data of various air quality monitoring units installed there. The study used the day-wise data of each pollutant from January 01,2020 , to May 31, 2020. The examination downloaded the information from the database of the Environmental Protection Agency (EPA) United States.

In this investigation, in order to analyze the impact of infrequent policy interference in the shape of lockdown (befallen due to COVID-19) on the air pollution of New York, five air pollutant variables such as $\mathrm{CO}, \mathrm{PM}_{2.5}, \mathrm{NO}_{2}$, $\mathrm{SO}_{2}$, and $\mathrm{O}_{3}$ have been investigated individually and as an assimilated index. Moreover, this investigation compared the fallouts of these concentrations for both before the lockdown and during the lockdown period. The EPA has established the air quality index (AQI), which is utilized to describe the excellence of air. The AQI is generally established through the pollutant standards, where the impact of a specific pollutant is captured in a single index by utilizing the correct accretion method (Ott 1978). This index contains the six categories that define health standards. Table 1 exhibited that an AQI holding the value of more than 300 signifies the hazardous quality of air, while the value of AQI less than 50 defines good quality of the air in the USA. According to Clean Air Act 1990, the AQI is comprised of five pollutants, i.e., carbon monoxide (CO), particulate matter $(\mathrm{PM}),{ }^{1}$ nitrogen dioxide $\left(\mathrm{NO}_{2}\right)$, sulfur dioxide $\left(\mathrm{SO}_{2}\right)$, and ground-level ozone $\left(\mathrm{O}_{3}\right)$. First, this investigation analyzed the variations in each pollutant before and during the lockdown period. Second, this study converted each pollutant into AQI to measure the health impact of each pollutant. Finally, the study combined all these air quality indices to reckon the environmental quality of New York called NYAQI. The investigators also compared the fallouts of these indices before and during the lockdown period so that

\footnotetext{
${ }^{1}$ Particulate matter (PM) consists of two categories, i.e., PM 2.5 and PM 10. However, this investigation includes $\mathrm{PM}_{2.5}$ only due to the unavailability of authenticated data of PM10.
} 
Table 1 Health concern define by EPA. Source: Environmental Protection Agency (EPA), USA

\begin{tabular}{|l|l|l|}
\hline Colors & AQI & Health Alarm \\
\hline Green & $0-50$ & Good \\
\hline Yellow & $51-100$ & Moderate \\
\hline Orange & $101-150$ & Unhealthy for Sensitive Groups \\
\hline Red & $151-200$ & Unhealthy \\
\hline Purple & $201-300$ & Very Unhealthy \\
\hline Maroon & $301-500$ & Hazardous \\
\hline
\end{tabular}

effective policies can be established. The AQI can be computed from each air pollutant as follows (EPA-OAQPS 2013),

$I=\frac{\iota_{\text {high }}-\iota_{\text {low }}}{\vartheta_{\text {high }}-\vartheta_{\text {low }}}\left(\vartheta-\vartheta_{\text {low }}\right)+\iota_{\text {low }}$

where $I$ indicates the AQI and $\vartheta$ specifies the pollutant concentration. Moreover, $\vartheta_{\text {low }}$ and $\vartheta_{\text {high }}$ designate the concentration breakpoint, which is $\leq \vartheta$ and $\geq \vartheta$, respectively. Additionally, $\iota_{\text {low }}$ and $\iota_{\text {high }}$ postulate the AQI breakpoint equivalent to $\vartheta_{\text {low }}$ and $\vartheta_{\text {high }}$, respectively. The breakpoints define by the Environmental Protection Agency are presented in Table 2. The next step of this examination is to formulate the NYAQI, which can be obtained through mathematical functions. These AQI can be combined through non-linear aggregation method, weighted additive method, minimum or maximum operator method, or root mean square method (Mahato et al. 2020),

Non-linear aggregated method;

NYAQI $=$ aggregated AQI $=\left[\sum \psi_{i}^{k}\right]^{\left(\frac{1}{k}\right)}(i=1, \ldots, n)$

here $\psi_{i}$ represents the AQI for $\mathrm{i}$ concentration, $k$ nominates the real positive value greater than unity, and $n$ elaborates the number of pollutants.
Weighted additive method;

$\mathrm{NYAQI}=$ aggregated AQI $=\left[\sum w i \psi_{i}\right]$

where $w$ represents the weight assign to each AQI while $\sum w i$ equals to 1 .

Root mean square method;

$$
\begin{aligned}
\text { NYAQI }=\text { aggregated AQI }= & {\left[1 / n\left(\psi_{1}^{2}+\psi_{2}^{2}\right.\right.} \\
& \left.+\psi_{3}^{2}, \ldots, \psi_{n}^{2}\right]^{0.5}
\end{aligned}
$$

Minimum or maximum operator method;

NYAQI $=$ Minimum or Maximum AQI

$$
=\left[\psi_{1}+\psi_{2}+\psi_{3}, \ldots . ., \psi_{n}\right]
$$

\section{Results and discussion}

\section{Gaging spatial pattern of each air pollutant before and during the lockdown period}

Figure 3 shows the spatial pattern of each pollutant before and

\begin{tabular}{|c|c|c|c|c|c|c|}
\hline $\mathrm{PM}_{2.5}\left(\mu \mathrm{g} / \mathrm{m}^{3}\right)$ & $\mathrm{CO}(\mathrm{ppm})$ & $\mathrm{O}_{3}(\mathrm{ppb})$ & $\mathrm{PM}_{10}\left(\mu \mathrm{g} / \mathrm{m}^{3}\right)$ & $\mathrm{SO}_{2}(\mathrm{ppb})$ & $\mathrm{NO}_{2}(\mathrm{ppb})$ & AQI \\
\hline$(24 \mathrm{~h})$ & $(8 \mathrm{~h})$ & $(8 \mathrm{~h})$ & $(24 \mathrm{~h})$ & $(1 \mathrm{~h})$ & $(1 \mathrm{~h})$ & -- \\
\hline$\vartheta_{\text {low }}-\vartheta_{\text {high }}$ & $\vartheta_{\text {low }}-\vartheta_{\text {high }}$ & $\vartheta_{\text {low }}-\vartheta_{\text {high }}$ & $\vartheta_{\text {low }}-\vartheta_{\text {high }}$ & $\vartheta_{\text {low }}-\vartheta_{\text {high }}$ & $\vartheta_{\text {low }}-\vartheta_{\text {high }}$ & $\vartheta_{\text {low }}-\vartheta_{\text {high }}$ \\
\hline $0.0-12.0$ & $0.0-4.4$ & $0-54$ & $0-54$ & $0-35$ & $0-53$ & $0-50$ \\
\hline $12.1-35.4$ & $4.5-9.4$ & $55-70$ & $55-154$ & $36-75$ & $54-100$ & $51-100$ \\
\hline $35.5-55.4$ & $9.5-12.4$ & $71-85$ & $155-254$ & $76-185$ & $101-360$ & $101-150$ \\
\hline $55.5-150.4$ & $1.5-15.4$ & $86-105$ & $255-354$ & $186-304$ & $361-649$ & $151-200$ \\
\hline $150.5-250.4$ & $15.5-30.4$ & $106-200$ & $355-424$ & $305-604(24 \mathrm{~h})$ & $650-1249$ & $201-300$ \\
\hline $250.5-350.4$ & $30.5-40.4$ & $405-504$ & $425-504$ & $605-804(24 \mathrm{~h})$ & $1250-1649$ & $301-400$ \\
\hline $350.5-500.4$ & $40.5-50.4$ & $505-604$ & $505-604$ & $805-1004(24 \mathrm{~h})$ & $1650-2049$ & $401-500$ \\
\hline
\end{tabular}
during the phase-1 lockdown epoch. The findings revealed

Table 2 Break points define by EPA

Source: Environmental Protection Agency (EPA), USA 
that the maximum concentration level of $\mathrm{CO}$ was $0.7 \mathrm{ppm}$ on March 09, 2020, but as President Donald Trump announced the emergency in the USA, CO concentration fell at the level of 0.25 ppm on March 17, 2020. However, after 1 day of lockdown in New York, on March 23, 2020, CO concentration decreased to $0.18 \mathrm{ppm}$ in the Bronx and New York County, representing a $74.2 \%$ reduction due to lockdown policy. The study acknowledged 52\% attenuation in $\mathrm{NO}_{2}$ concentration on March 23, 2020, compared to March 09, 2020, in New York. Also, the inquiry discovered that the concentration level of $\mathrm{PM}_{2.5}$ was $10.3 \mu \mathrm{g} / \mathrm{m}^{3}$ and $8.0 \mu \mathrm{g} / \mathrm{m}^{3}$ on March 09, 2020, and March 17, 2020, respectively, though, as the lockdown announced in New York, the concentration level of $\mathrm{PM}_{2.5}$ reduced to $4.0 \mu \mathrm{g} / \mathrm{m}^{3}$ on March 23, 2020. Moreover, on March 31, 2020, it showed a maximum level of $4.5 \mu \mathrm{g} / \mathrm{m}^{3}$. Nevertheless, the analysis reported that there was a significant increase in the ozone concentration. Notably, the study noted $0.029 \mathrm{ppb}$ value of $\mathrm{O}_{3}$ concentration on March 09, 2020, and 0.025 ppb value of $\mathrm{O}_{3}$ concentration on March 17, 2020, while it reached up to $0.0312 \mathrm{ppb}$ and 0.0300 ppb on March 23, 2020, and March 31, 2020, respectively. These values elaborate that there was a $50 \%$ increase in the concentration level of $\mathrm{O}_{3}$ during the 1st phase of lockdown in New York. The examination demarcated a $73 \%$ decline in sulfur dioxide on March 23, 2020, compared to March 09, 2020. However, on March 31, 2020, $\mathrm{SO}_{2}$ concentration amplified due to the end of phase-1 lockdown. Hence, these sightings declared that the 1 st phase of lockdown from March 22, 2020, to March 31, 2020, has drastically improved the environmental conditions in New York. However, the analysis of phase-1 does not reveal the full significance of lockdown in New York. Consequently, the investigation converted each air pollutant into an air quality index and compared their fallouts before and during the complete lockdown era, so that an enormous impact of lockdown can be captured.

\section{Changes in the sub-AQI of each air pollutant before and during the lockdown period}

Figure 4 demonstrated the AQI for each pollutant analyzed in this investigation. The findings stated that lockdown befallen due to COVID-19 has expressively improved the air quality in New York City. Remarkably, the air quality index generated through 8-h daily average values of carbon monoxide (AQI $\mathrm{CO})$ stated that it has a mean value of 5.04 before the lockdown period. Still, as the lockdown began on March 23, 2020, it faced a sudden reduction in its value, and the average value of AQI CO remains 2.53 during the lockdown period. Mahato et al. (2020) analyzed the impact of lockdown on air quality in NCT Delhi and found a significant decline in $\mathrm{CO}, \mathrm{NO}_{2}, \mathrm{NH}_{3}$, $\mathrm{SO}_{2}$, and $\mathrm{PM}_{2.5}$. The outcomes of $\mathrm{NO}_{2}$ revealed a $33.6 \%$ decrease in the average value of $\mathrm{AQI} \mathrm{NO}_{2}$ during the lockdown period. Shehzad et al. (2020) revealed that $\mathrm{NO}_{2}$ concentration has momentously decreased in Delhi and Mumbai during the lockdown period.

Moreover, Sarfraz and Shehzad (2020) evaluated the nonlinear behavior of COVID-19 cases on $\mathrm{NO}_{2}$ concentration and documented that an increase in COVID-19 cases decreases the level of $\mathrm{NO}_{2}$ concentration in New York. Besides, the level of $\mathrm{AQI} \mathrm{PM}_{2.5}$ showed a significant decline in its value during the lockdown period. The study noted an average reduction of $47.72 \%$ in the air quality index of $\mathrm{PM}_{2.5}$, inferring that COVID-19 has imperatively upsurged air quality in New York. Also, the inspection publicized that lockdown has evocatively intensified the level of ozone $\left(\mathrm{O}_{3}\right)$ in New York City. The study exposed that there was a $44.4 \%$ increase in groundlevel ozone. This proliferation in ozone concentration results from deterioration in the level of nitrogen oxide (NO), which leads to diminishing the consumption of ozone $\left(\mathrm{NO}+\mathrm{O}_{3}=\right.$ $\mathrm{NO}_{2}+\mathrm{O}_{2}$ ) and results in an upsurge in the level of groundlevel ozone concentration.

On the other hand, the upshots of $\mathrm{SO}_{2}$ documented a $59.68 \%$ reduction in the mean value of $\mathrm{AQI} \mathrm{SO}_{2}$ during the lockdown period in New York. Mahato and Ghosh (2020) stated that lockdown improved air quality in almost $80 \%$ of India's cities. Additionally, $\mathrm{NO}, \mathrm{PM}_{2.5}, \mathrm{NO}_{2}$, and $\mathrm{PM}_{10}$ concentrations have decreased to $50 \%$ due to lockdown in India. These findings confirmed that the lockdown that happened due to novel coronavirus has significantly improved the environmental quality in New York City.

\section{Variations in the NYAQI before and during the lockdown period}

The NYAQI represents the complete index of air quality in New York. This index can be utilized to ascertain the overall level of air quality in New York. The results of Fig. 5 discovered that overall air quality in New York City had been improved during the lockdown period. The mean value of NYAQI decreased from 18.65 to 14.97 during the lockdown era, which indicates that air quality in New York has been increased by $19.73 \%$ on average due to lockdown. Subsequently, isolation, the shutdown of public transportation, industrial units, hotels, and restaurants substantially escalate the environmental excellence in New York. Sarfraz and Shehzad (2020) revealed that lockdown has imperatively decreased the level of $\mathrm{NO}_{2}$ concentration in New York. Moreover, the study stated that a decrease in population also improves the environmental quality in New York.

\section{Review of year-wise and county-wise air quality and healthy days in New York}

Table 3 epitomizes the yearly and county-wise variations in the air quality of New York. The aftermath revealed that the maximum air quality index of Bronx County had been 
(a)

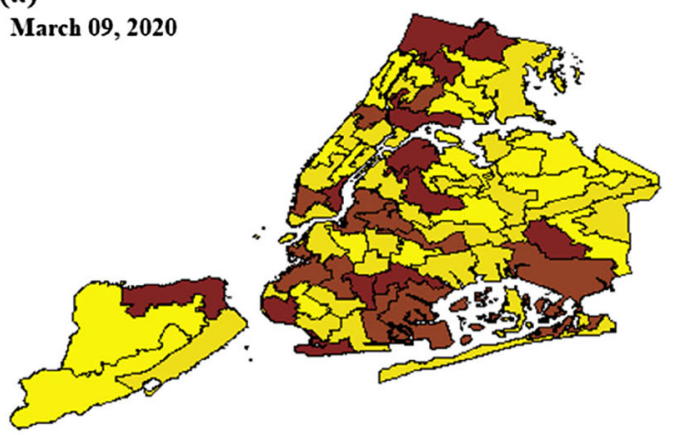

CO Concentration in New York

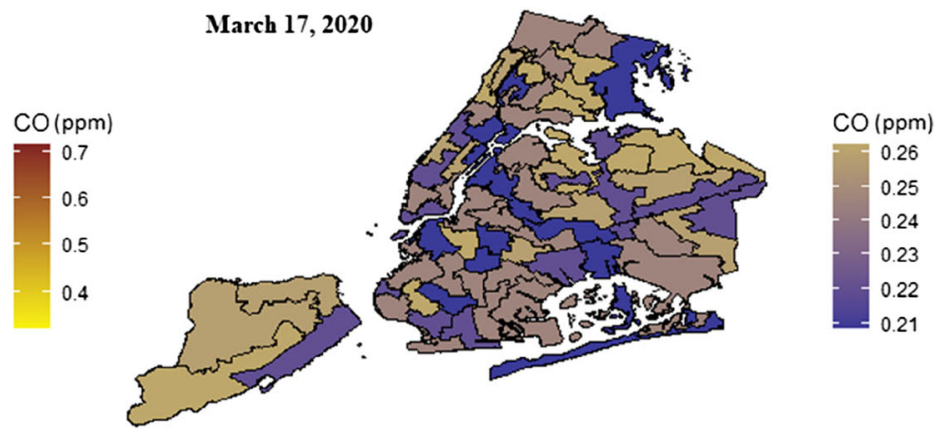

Lockdown Started
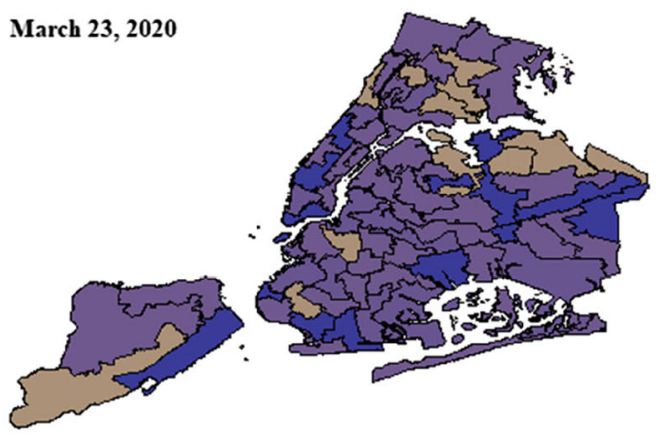

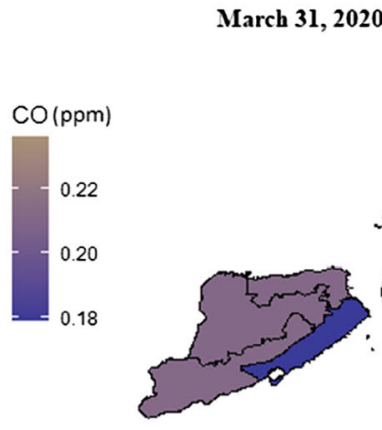

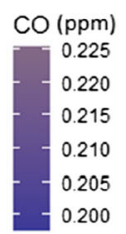

(b)

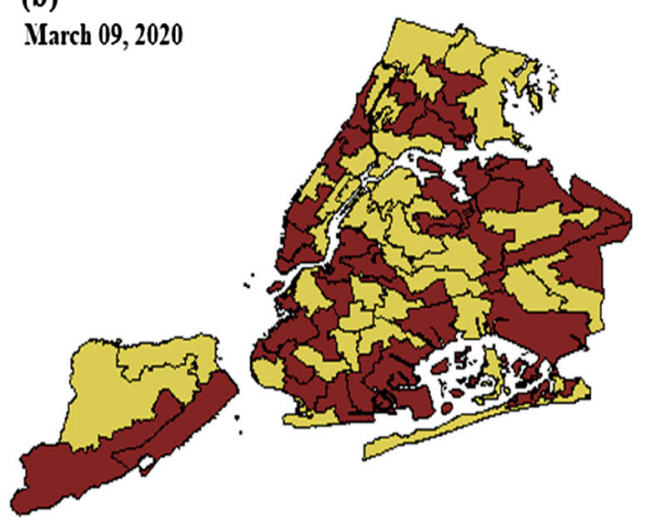

NO2 Concentration in New York

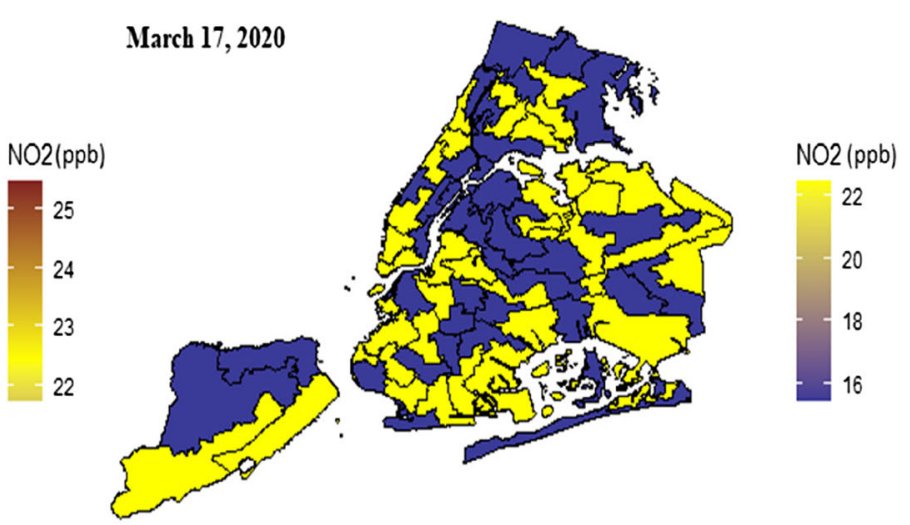

Lockdown Started
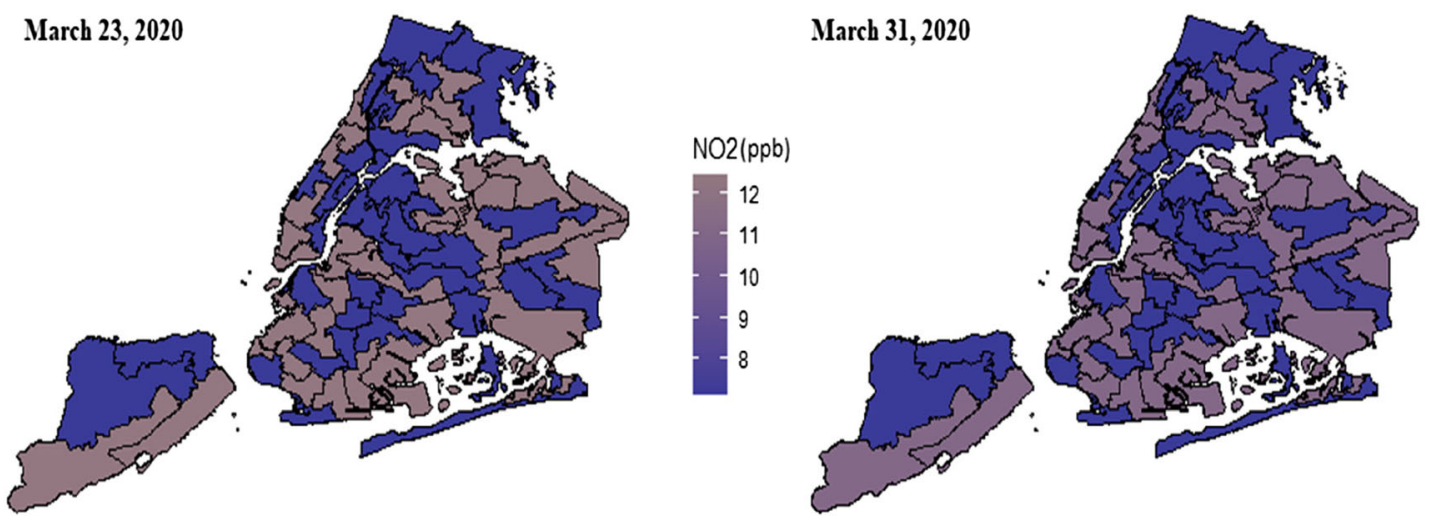

$\mathrm{NO2}(\mathrm{ppb})$

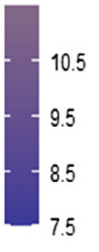

Fig. 3 Spatial pattern of $\mathrm{CO}, \mathrm{NO}_{2}, \mathrm{O}_{3}, \mathrm{PM}_{2.5}$, and $\mathrm{SO}_{2}$ before lockdown and during phase-1 of lockdown. Source: Author's calculation 


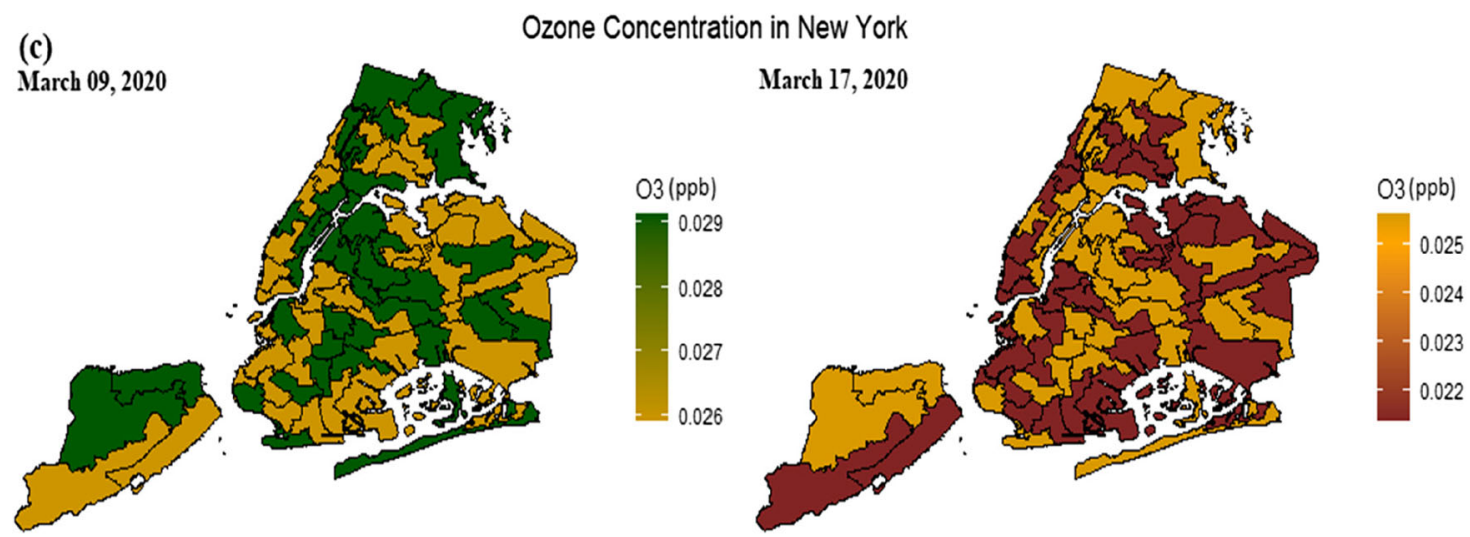

Lockdown Started
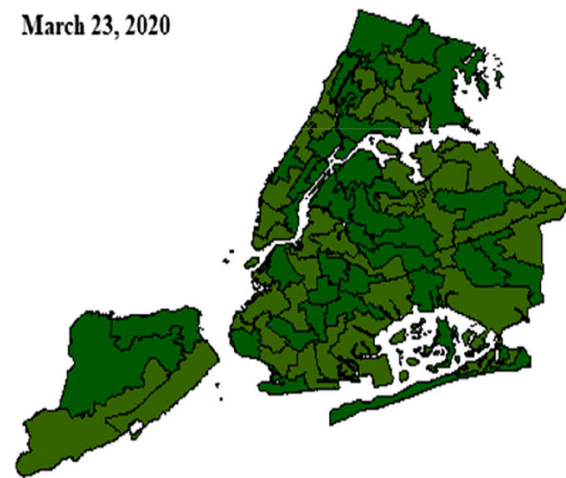

March 31, 2020

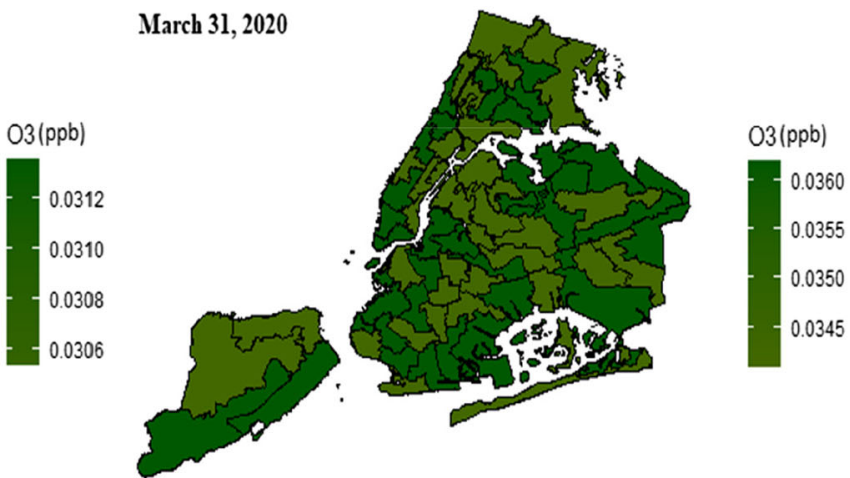

(d)

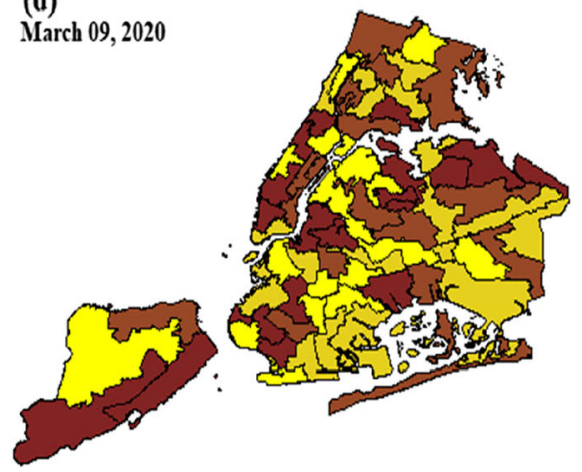

PM2.5 Concentration in New York
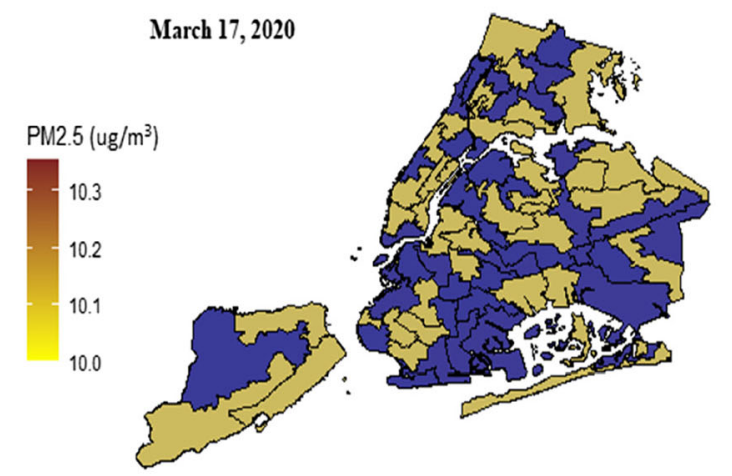

Lockdown Started
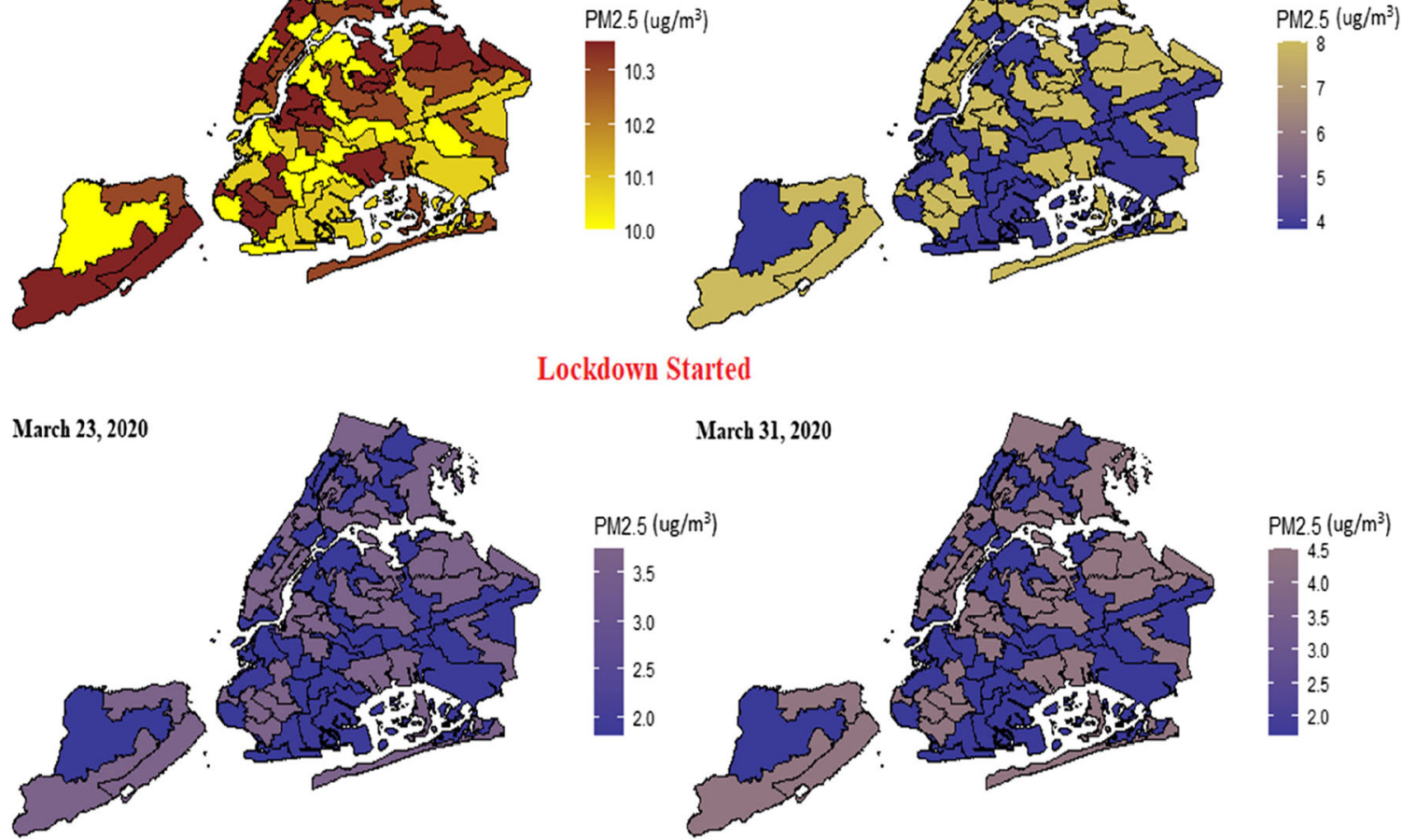

Fig. 3 (continued) 
(e)

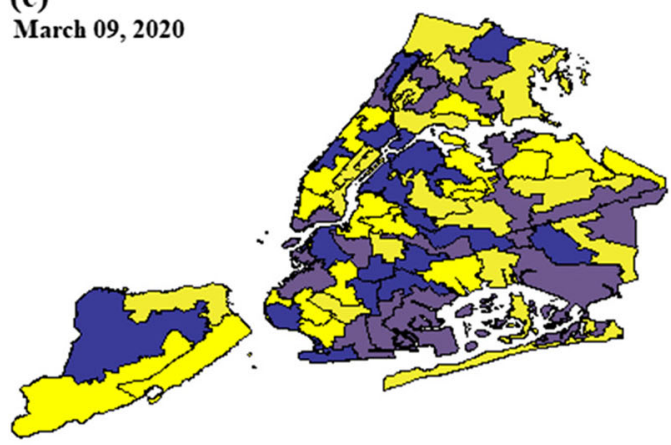

SO2 Concentration in New York

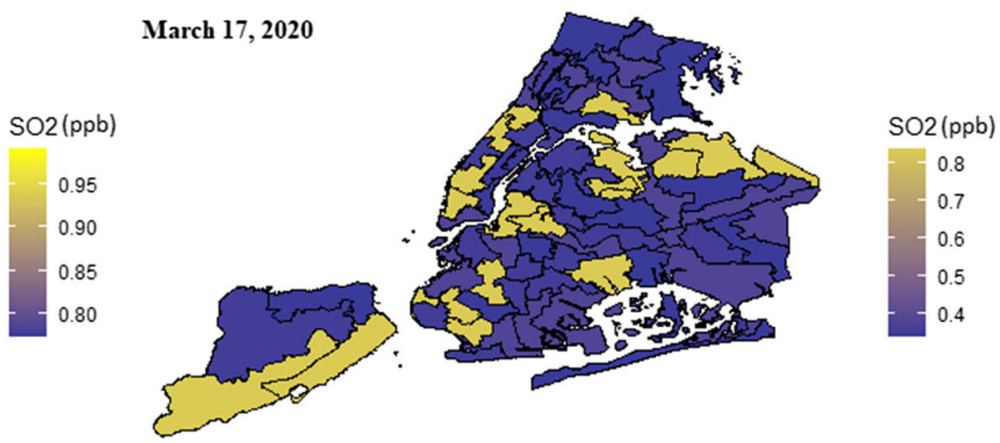

Lockdown Started
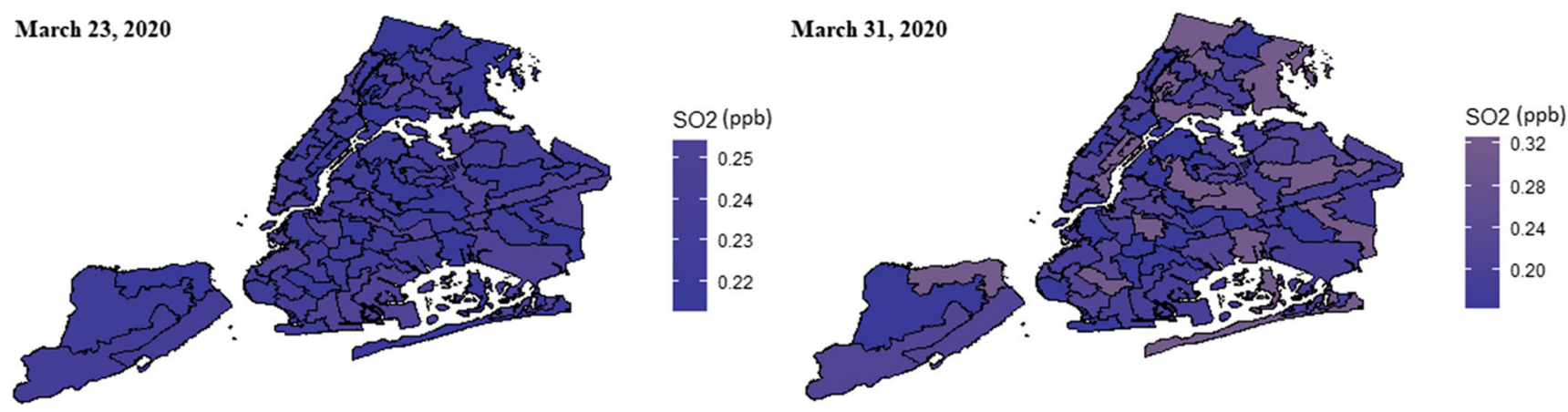

Fig. 3 (continued)

diminished by $48.6 \%$ in the first 92 days of 2020 compared to 2018. Furthermore, Brooklyn, Manhattan, Queens, and Staten Island County encountered $18.75 \%, 55.62 \%, 47.14 \%$, and
$47 \%$ decrease in air quality index, respectively, due to lockdown as compared to 2018. The results revealed that in 2020, 72 out of 92 days in Bronx County are categorized in Good
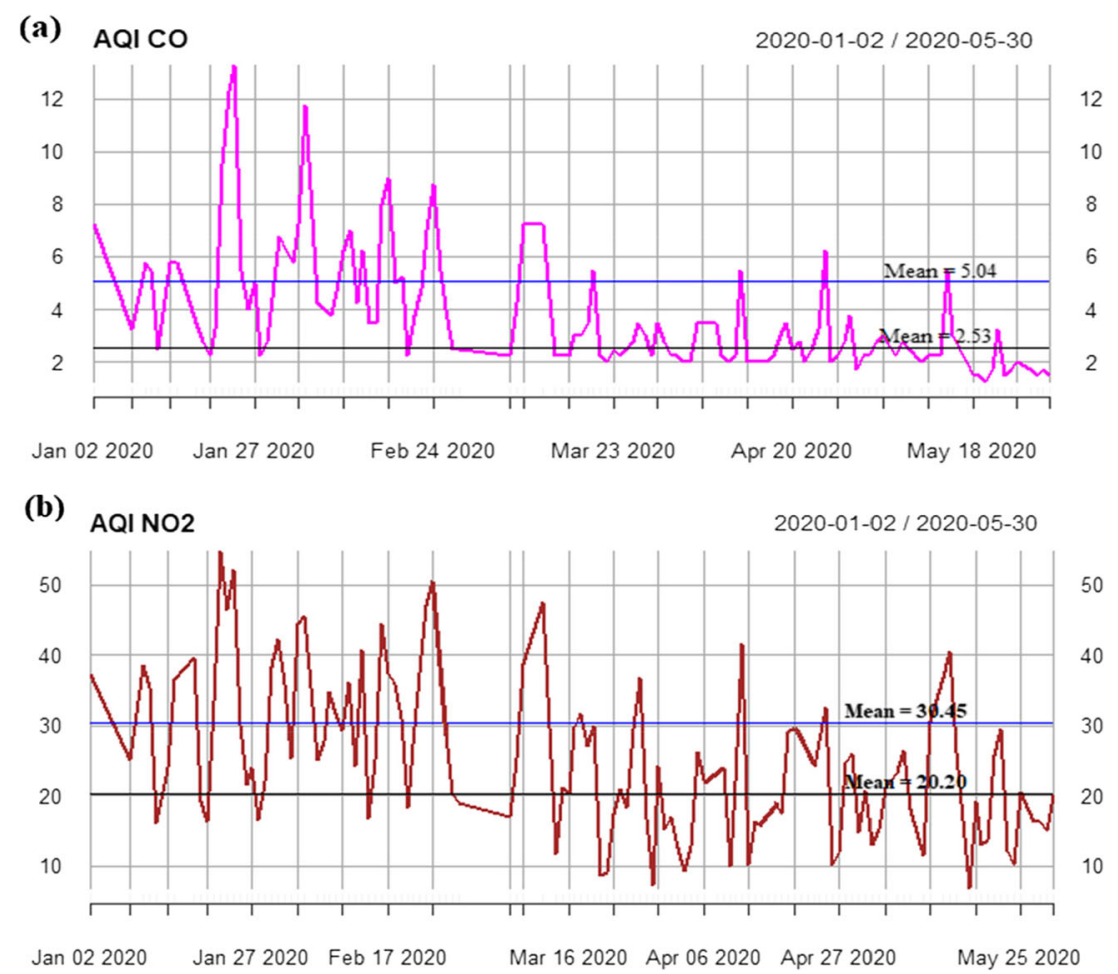

Fig. 4 Air quality index of each pollutant before and during lockdown period. Source: Author's calculation 
(c) AQI OZONE (03)

$2020-01-02 / 2020-05-30$

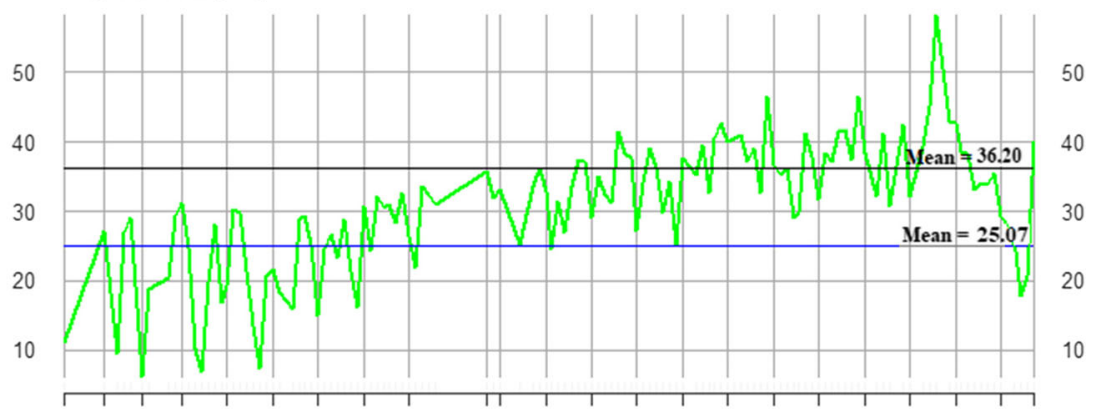

Jan $022020 \quad$ Jan 272020 Feb $172020 \quad$ Mar 162020 Apr 062020 Apr $272020 \quad$ May 252020

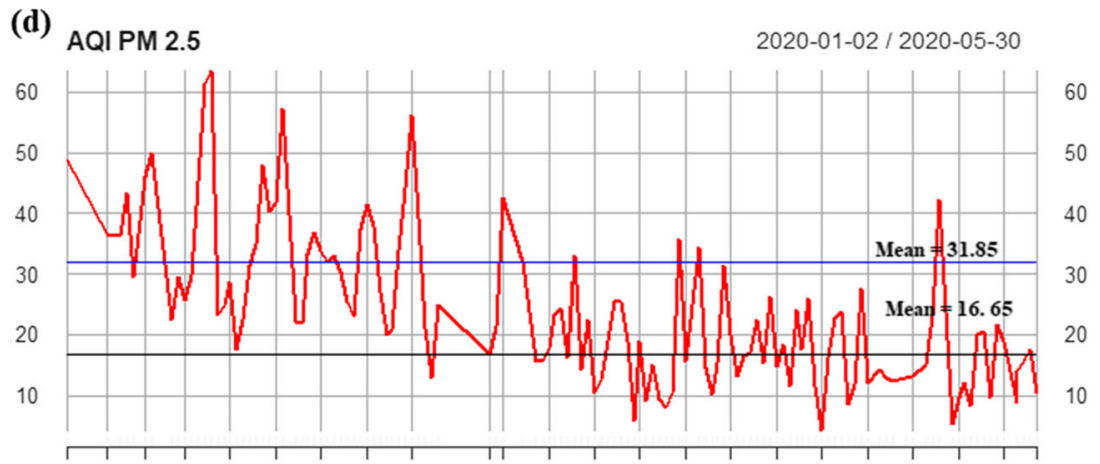

Jan 022020 Jan 272020 Feb $172020 \quad$ Mar 162020 Apr 062020 Apr $272020 \quad$ May 252020

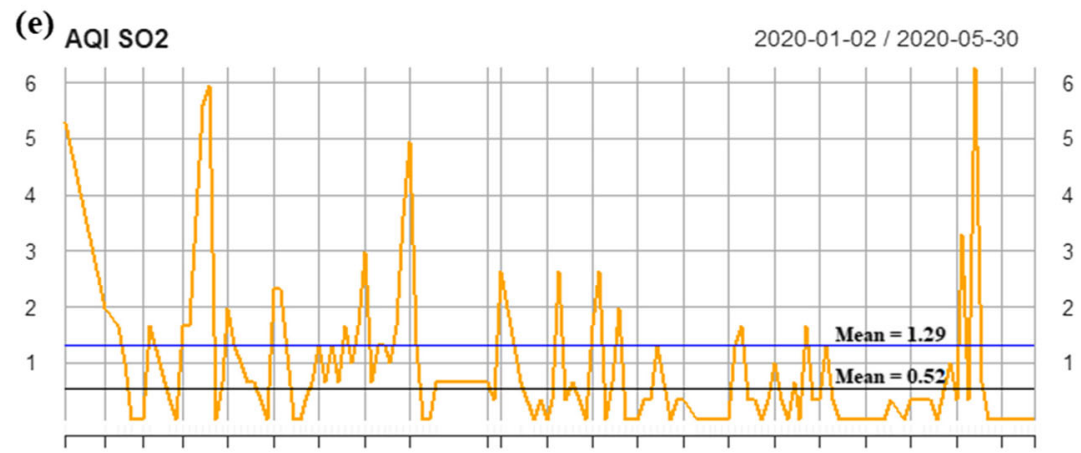

Jan 022020 Jan 272020 Feb $172020 \quad$ Mar 162020 Apr 062020 Apr $272020 \quad$ May 252020

Fig. 4 (continued)

Fig. 5 Variation in NYAQI before and during the lockdown period. Source: Author's calculation

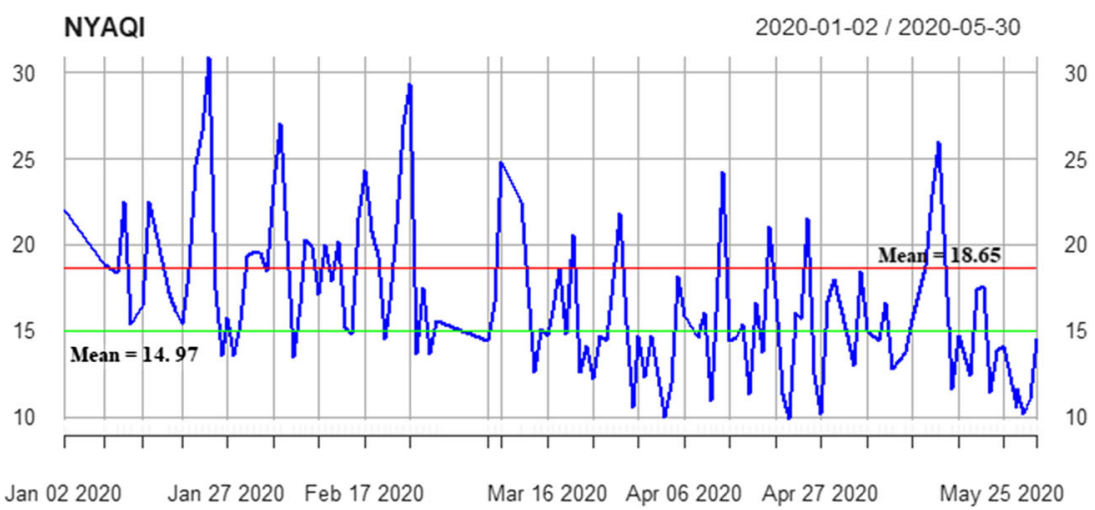


Table 3 Year-wise analysis of AQI in New York

\begin{tabular}{|c|c|c|c|c|c|c|c|c|c|}
\hline County & Year & $\begin{array}{l}\text { Days with } \\
\text { AQI }\end{array}$ & $\begin{array}{l}\text { Good } \\
\text { Days }\end{array}$ & $\begin{array}{l}\text { Moderate } \\
\text { Days }\end{array}$ & $\begin{array}{l}\text { Unhealthy for Sensitive } \\
\text { Groups Days }\end{array}$ & $\begin{array}{l}\text { Unhealthy } \\
\text { Days }\end{array}$ & $\begin{array}{l}\text { Very Unhealthy } \\
\text { Days }\end{array}$ & $\begin{array}{l}\text { Hazardous } \\
\text { Days }\end{array}$ & $\begin{array}{l}\text { Max } \\
\text { AQI }\end{array}$ \\
\hline Bronx & 2018 & 365 & 286 & 70 & 9 & 0 & 0 & 0 & 150 \\
\hline Brooklyn & 2018 & 365 & 330 & 35 & 0 & 0 & 0 & 0 & 80 \\
\hline Manhattan & 2018 & 365 & 255 & 99 & 10 & 1 & 0 & 0 & 151 \\
\hline Queens & 2018 & 365 & 288 & 69 & 8 & 0 & 0 & 0 & 140 \\
\hline $\begin{array}{l}\text { Staten } \\
\text { Island }\end{array}$ & 2018 & 363 & 286 & 71 & 6 & 0 & 0 & 0 & 136 \\
\hline Bronx & 2019 & 365 & 280 & 82 & 3 & 0 & 0 & 0 & 115 \\
\hline Brooklyn & 2019 & 365 & 335 & 30 & 0 & 0 & 0 & 0 & 75 \\
\hline Manhattan & 2019 & 365 & 293 & 70 & 2 & 0 & 0 & 0 & 136 \\
\hline Queens & 2019 & 365 & 292 & 69 & 4 & 0 & 0 & 0 & 119 \\
\hline $\begin{array}{l}\text { Staten } \\
\text { Island }\end{array}$ & 2019 & 365 & 314 & 51 & 0 & 0 & 0 & 0 & 97 \\
\hline Bronx & 2020 & 92 & 72 & 20 & 0 & 0 & 0 & 0 & 77 \\
\hline Brooklyn & 2020 & 91 & 82 & 9 & 0 & 0 & 0 & 0 & 65 \\
\hline Manhattan & 2020 & 92 & 78 & 14 & 0 & 0 & 0 & 0 & 67 \\
\hline Queens & 2020 & 92 & 81 & 11 & 0 & 0 & 0 & 0 & 74 \\
\hline $\begin{array}{l}\text { Staten } \\
\text { Island }\end{array}$ & 2020 & 89 & 79 & 10 & 0 & 0 & 0 & 0 & 72 \\
\hline
\end{tabular}

Source: Environmental Protection Agency. Note: Here, AQI represents the amalgamation of CO, $\mathrm{PM}_{2.5}, \mathrm{PM}_{10}, \mathrm{SO}_{2}, \mathrm{O}_{3}$, and $\mathrm{NO}_{2}$ generated by EPA

Days as per health meter of EPA, and rough no day falls in unhealthy class. Likewise, in Bronx County, 280 out of 365 days are known to be Good Days, 82 days are categorized as Moderate Days, and 3 days fall in the Unhealthy for Sensitive Group category of EPA's health index in 2019. Conversely, Brooklyn, Manhattan, Queens, and Staten Island reported 82 days, 78 days, 81 days, and 79 days as Good Days in 2020. Hence, these judgments confirmed that lockdown in New York has imperatively increased environmental quality.

\section{Conclusion}

The study highlights that while the world is battling against the COVID-19 and facing substantial economic losses due to decreased coherent work situations, the air quality benefits. The exposure and impact assessment of lockdown is performed on New York City's air quality, one of the most populated cities in the USA, with an estimated 2019 population of $8,336,817$, distributed over $302.6 \mathrm{mi}^{2}$. Due to the contagion of COVID-19, a complete lockdown is imposed in New York from March 22 up to March 31 and later extended to May 15, which has encouraged the author to evaluate the impact of lockdown on the air quality of New York City. This investigation utilized the daily average data of $\mathrm{CO}(8 \mathrm{~h}), \mathrm{NO}_{2}(1 \mathrm{~h}), \mathrm{PM}_{2.5}(24 \mathrm{~h}), \mathrm{O}_{3}(8 \mathrm{~h})$, and $\mathrm{SO}_{2}(1 \mathrm{~h})$ to determine the air quality before and during the
COVID-19 period. The study utilized the data from January 01, 2020, to May 31, 2020. The investigation revealed that the concentration level of $\mathrm{CO}$ had been decreased from 0.7 to $0.22 \mathrm{ppm}$ during the lockdown period. $\mathrm{NO}_{2}$ concentration faced a decline in its value from 25 to $12 \mathrm{ppb}$ due to the lockdown that happened due to the COVID-19 pandemic. However, the level of $\mathrm{O}_{3}$ has been augmented during the COVID-19 period from the concentration level of $0.02 \mathrm{ppb}$ to 0.03 . The examination discovered that a decrease in $\mathrm{NO}_{2}$ concentration has imperatively upsurge the ground-level ozone.

Similarly, the study quantified that the concentration level of $\mathrm{SO}_{2}$ and $\mathrm{PM}_{2.5}$ have reduced from 0.95 to $0.25 \mathrm{ppb}$ and $10.3^{3}$ to $3.5 \mu \mathrm{g} / \mathrm{m}^{3}$, respectively. On the other hand, the investigation converted each pollutant into an air quality index to ascertain the impact of lockdown on air pollution in New York. The study found that the mean value of AQI CO dwindled from 5.04 to 2.53, while the mean value of AQI $\mathrm{NO}_{2}$ shrunk from 30.45 to 20.20 . Nonetheless, the average air quality index of $\mathrm{O}_{3}$ has been concentrated from 25.07 to 36.20 during the lockdown period in New York. Furthermore, the mean value of $\mathrm{AQI} \mathrm{SO} \mathrm{SO}_{2}$ and $\mathrm{AQI} \mathrm{PM} \mathrm{PM}_{2.5}$ lessened from 1.29 to 0.52 and 31.85 to 16.65 , respectively. The on hand investigation assessed the overall environmental quality in New York and found that the mean value of the New York air quality index (NYAQI) has been contracted from 18.65 to 14.97 during the lockdown period. The study evaluated the year-wise air quality in New York and discovered that AQI had been 
declined by $48.6 \%, 18.75 \%, 55.62 \%, 47.14 \%$, and $47 \%$ in the Bronx, Brooklyn, Manhattan, Queens, and Staten Island county of New York in 2020 as compared to 2018, respectively. These findings inveterate that lockdown happened due to COVID-19 has proved to be a blessing for the environmental features in New York City.

Based on the results, this study recommends that the New York City government should design a regional joint-emission control plan rather than sporadic and abrupt interventions to improve the environmental quality. The government should create awareness about a clean environment among their citizens and include environmental-related coursework in primary education in general; it will be the preferred option to reduce air pollution. Finally, authorities need to review their health and environmental policies, taking into account some of the lockdown's negative economic and social consequences (Balsalobre-Lorente et al. 2020).

We investigated the impact of lockdown on air quality during COVID-19 for New York City. As this paper is being written, the pandemic continues, and the second wave is experienced globally in the number of cases. In many megacities, the government takes various measures, and these measures cause a lockdown. Hence, more information is needed on the effects of COVID-19. Future research can focus on the economic, social, and environmental impacts of COVID-19 and lockdown. More evaluation and empirical papers can be offered.

Author contributions K.S.: conceptualization, data curation, project administration, writing - original draft

F.B.: data curation, project administration, writing - original draft

E.K.: methodology, data curation, writing - original draft

L.X.: data curation, project administration, writing — original draft

M.A.: methodology, data curation, visualization, writing - original draft, revision

Funding The study is supported by the National Natural Science Foundation of China (No.71673043).

Data availability The datasets used and/or analyzed during the current study are available from the corresponding author on reasonable request.

\section{Declarations}

Ethics approval and consent to participate This article does not contain any studies with human participants or animals performed by any of the authors.

Consent to publish All authors have consent for the publication of the manuscript.

Consent to participate All authors contributed voluntarily to this study.

Competing interests The authors declare no competing interests.

\section{References}

Baldasano JM (2020) COVID-19 lockdown effects on air quality by NO2 in the cities of Barcelona and Madrid (Spain). Sci Total Environ 741:140353. https://doi.org/10.1016/j.scitotenv.2020.140353

Balsalobre-Lorente D, Driha OM, Bekun FV, Sinha A, Adedoyin FF (2020) Consequences of COVID-19 on the social isolation of the Chinese economy: accounting for the role of reduction in carbon emissions. Air Qual Atmos Health 13:1-13. https://doi.org/10. 1007/s11869-020-00898-4

Bao R, Zhang A (2020) Does lockdown reduce air pollution? Evidence from 44 cities in northern China. Sci Total Environ 731:139052. https://doi.org/10.1016/j.scitotenv.2020.139052

Blondet I, Schreck E, Viers J, Casas S, Jubany I, Bahí N, Zouiten C, Dufréchou G, Freydier R, Galy-Lacaux C, Martínez-Martínez S, Faz A, Soriano-Disla M, Acosta JA, Darrozes J (2019) Atmospheric dust characterisation in the mining district of Cartagena-La Unión, Spain: air quality and health risks assessment. Sci Total Environ 693:133496. https://doi.org/10.1016/j.scitotenv. 2019.07.302

Bowatte G, Lodge CJ, Knibbs LD et al (2017) Traffic-related air pollution exposure is associated with allergic sensitization, asthma, and poor lung function in middle age. J Allergy Clin Immunol 139:122129.e1. https://doi.org/10.1016/j.jaci.2016.05.008

Broomandi P, Karaca F, Nikfal A, Jahanbakhshi A, Tamjidi M, Kim JR (2020) Impact of COVID-19 event on the air quality in Iran. Aerosol Air Qual Res 20:1793-1804. https://doi.org/10.4209/aaqr.2020.05. 0205

Chakraborty I, Maity P (2020) COVID-19 outbreak: migration, effects on society, global environment and prevention. Sci Total Environ 728: 138882. https://doi.org/10.1016/j.scitotenv.2020.138882

Chauhan A, Singh RP (2020) Decline in PM2.5 concentrations over major cities around the world associated with COVID-19. Environ Res 187:109634. https://doi.org/10.1016/j.envres.2020.109634

Dantas G, Siciliano B, França BB, da Silva CM, Arbilla G (2020) The impact of COVID-19 partial lockdown on the air quality of the city of Rio de Janeiro, Brazil. Sci Total Environ 729:139085. https://doi. org/10.1016/j.scitotenv.2020.139085

Dedeoğlu M, Koçak E, Ulucak ZŞ (2021) The impact of immigration on human capital and carbon dioxide emissions in the USA: an empirical investigation. Air Qual Atmos Health 1-10. https://doi.org/10. 1007/s11869-020-00973-w

Deng H, Eckel SP, Liu L, Lurmann FW, Cockburn MG, Gilliland FD (2017) Particulate matter air pollution and liver cancer survival. Int J Cancer 141:744-749. https://doi.org/10.1002/ijc.30779

Depietri Y, McPhearson T (2018) Changing urban risk: 140 years of climatic hazards in New York City. Clim Chang 148:95-108. https://doi.org/10.1007/s10584-018-2194-2

EPA-OAQPS (2013) Technical Assistance Document for the reporting of daily AQI

Fareed Z, Iqbal N, Shahzad F et al (2020) Co-variance nexus between COVID-19 mortality, humidity, and air quality index in Wuhan, China: new insights from partial and multiple wavelet coherence. Air Qual Atmos Health 13:673-682

Fu F, Purvis-Roberts KL, Williams B (2020) Impact of the COVID-19 pandemic lockdown on air pollution in 20 major cities around the world. Atmosphere (Basel) 11:1189. https://doi.org/10.3390/ atmos11111189

Gilderbloom JH, Meares WL, Squires GD (2020) Pollution, place, and premature death: evidence from a mid-sized city. Local Environ 25: 419-432. https://doi.org/10.1080/13549839.2020.1754776

He G, Pan Y, Tanaka T (2020) The short-term impacts of COVID-19 lockdown on urban air pollution in China. Nat Sustain 3:10051011. https://doi.org/10.1038/s41893-020-0581-y 
Johnson S, Ross Z, Kheirbek I, Ito K (2020) Characterization of intraurban spatial variation in observed summer ambient temperature from the New York City Community Air Survey. Urban Clim 31: 100583. https://doi.org/10.1016/j.uclim.2020.100583

Karuppasamy MB, Seshachalam S, Natesan U, Ayyamperumal R, Karuppannan S, Gopalakrishnan G, Nazir N (2020) Air pollution improvement and mortality rate during COVID-19 pandemic in India: global intersectional study. Air Qual Atmos Health 13: 1375-1384. https://doi.org/10.1007/s11869-020-00892-w

Khoo EJ, Lantos JD (2020) Lessons learned from the COVID-19 pandemic. Acta Paediatr 109:1323-1325. https://doi.org/10.1111/apa. 15307

Kinnon MM, Zhu S, Carreras-Sospedra M et al (2019) Considering future regional air quality impacts of the transportation sector. Energy Policy 124:63-80. https://doi.org/10.1016/j.enpol.2018.09.011

Koçak E, Kızılkaya O (2020) Towards sustainable development in China: do political rights and civil liberties matter for environmental quality? Environ Sci Pollut Res 27:1-13. https://doi.org/10.1007/ s11356-020-09813-x

Li T, Li Y, An D, Han Y, Xu S, Lu Z, Crittenden J (2019) Mining of the association rules between industrialization level and air quality to inform high-quality development in China. J Environ Manag 246: 564-574. https://doi.org/10.1016/j.jenvman.2019.06.022

Ma C-J, Kang G-U (2020) Air quality variation in Wuhan, Daegu, and Tokyo during the explosive outbreak of COVID-19 and its health effects. Int J Environ Res Public Health 17:4119. https://doi.org/10. 3390/ijerph17114119

Mahato S, Ghosh KG (2020) Short-term exposure to ambient air quality of the most polluted Indian cities due to lockdown amid SARSCoV-2. Environ Res 188:109835. https://doi.org/10.1016/j.envres. 2020.109835

Mahato S, Pal S, Ghosh KG (2020) Effect of lockdown amid COVID-19 pandemic on air quality of the megacity Delhi, India. Sci Total Environ 730:139086. https://doi.org/10.1016/j.scitotenv.2020. 139086

Masiol M, Hopke PK, Felton HD, Frank BP, Rattigan OV, Wurth MJ, LaDuke GH (2017) Analysis of major air pollutants and submicron particles in New York City and Long Island. Atmos Environ 148: 203-214. https://doi.org/10.1016/j.atmosenv.2016.10.043

Miranda ML, Edwards SE, Keating MH, Paul CJ (2011) Making the environmental justice grade: the relative burden of air pollution exposure in the United States. Int J Environ Res Public Health 8:17551771. https://doi.org/10.3390/ijerph8061755

Miri M, Derakhshan Z, Allahabadi A, Ahmadi E, Oliveri Conti G, Ferrante M, Aval HE (2016) Mortality and morbidity due to exposure to outdoor air pollution in Mashhad metropolis, Iran. The AirQ model approach. Environ Res 151:451-457. https://doi.org/10. 1016/j.envres.2016.07.039

National Aeronautics and Space Administration (NASA) (2020). https:// airquality.gsfc.nasa.gov/. Accessed 26 April 2020.

Nazaroff WW, Weschler CJ (2004) Cleaning products and air fresheners: exposure to primary and secondary air pollutants. Atmos Environ 38:2841-2865. https://doi.org/10.1016/j.atmosenv.2004.02.040

Ott WR (1978) Environmental indices: theory and practice. Environ Indices Theory Pract 14:1453-1454. https://doi.org/10.1016/00046981(80)90167-5

Park S, Allen RJ, Lim CH (2020) A likely increase in fine particulate matter and premature mortality under future climate change. Air
Qual Atmos Health 13:143-151. https://doi.org/10.1007/s11869019-00785-7

Pata UK (2020) How is COVID-19 affecting environmental pollution in US cities? Evidence from asymmetric Fourier causality test. Air Qual Atmos Health 13:1-7. https://doi.org/10.1007/s11869-02000877-9

Perera F, Berberian A, Cooley D, Shenaut E, Olmstead H, Ross Z, Matte $T$ (2021) Potential health benefits of sustained air quality improvements in New York City: a simulation based on air pollution levels during the COVID-19 shutdown. Environ Res 193:110555. https:// doi.org/10.1016/j.envres.2020.110555

Plane DA, Mu W (2020) A people-based density perspective on physical/ virtual world spaces in the microcosmic city Land Use Policy 104462. https://doi.org/10.1016/j.landusepol.2020.104462

Sarfraz M, Shehzad K (2020) Gauging the air quality of New York : a non-linear Nexus between COVID-19 and nitrogen dioxide emission

Shehzad K, Sarfraz M, Ghulam S, Shah M (2020) The impact of COVID19 as a necessary evil on air pollution in India. Environ Pollut 266: 115080. https://doi.org/10.1016/j.envpol.2020.115080

Sitaras IE, Siskos PA (2008) The role of primary and secondary air pollutants in atmospheric pollution: Athens urban area as a case study. Environ Chem Lett 6:59-69

Solinas-Saunders M (2020) The U.S. Federal response to COVID-19 during the first 3 months of the outbreak: was an evidence-based approach an option? Am Rev Public Adm 50(6-7):713-719. https:// doi.org/10.1177/0275074020942408

Suhaimi NF, Jalaludin J, Latif MT (2020) Demystifying a possible relationship between COVID-19, air quality and meteorological factors: evidence from Kuala Lumpur, Malaysia. Aerosol Air Qual Res 20: 1520-1529. https://doi.org/10.4209/aaqr.2020.05.0218

Wang C, Horby PW, Hayden FG, Gao GF (2020) A novel coronavirus outbreak of global health concern. Lancet 395:470-473

WHO (2014) 7 million premature deaths annually linked to air pollution. World Heath Organ

WHO (2020) Coronavirus disease (COVID-19) Situation Report-194

Yang J, Shi B, Zheng Y, Shi Y, Xia G (2020) Urban form and air pollution disperse: key indexes and mitigation strategies. Sustain Cities Soc 57:101955. https://doi.org/10.1016/j.scs.2019.101955

Zangari S, Hill DT, Charette AT, Mirowsky JE (2020) Air quality changes in New York City during the COVID-19 pandemic. Sci Total Environ 742:140496. https://doi.org/10.1016/j.scitotenv.2020. 140496

Zhang C, Ding R, Xiao C, Xu Y, Cheng H, Zhu F, Lei R, di D, Zhao Q, Cao J (2017) Association between air pollution and cardiovascular mortality in Hefei, China: a time-series analysis. Environ Pollut 229: 790-797. https://doi.org/10.1016/j.envpol.2017.06.022

Zhu N, Zhang D, Wang W, Li X, Yang B, Song J, Zhao X, Huang B, Shi W, Lu R, Niu P, Zhan F, Ma X, Wang D, Xu W, Wu G, Gao GF, Tan W, China Novel Coronavirus Investigating and Research Team (2020) A novel coronavirus from patients with pneumonia in China, 2019. N Engl J Med 382:727-733. https://doi.org/10.1056/ NEJMoa2001017

Publisher's note Springer Nature remains neutral with regard to jurisdictional claims in published maps and institutional affiliations. 